\title{
Early Conversations and Word Learning: Contributions from Child and Adult ${ }^{1}$
}

\author{
Lois Bloom, Cheryl Margulis, Erin Tinker, Naomi Fujita \\ Teachers College, Columbia University
}

Citation: Bloom, L., Margulis, C., Tinker, E., \& Fujita, N. (1996). Early conversations and word learning: Contributions from child and adult. Child Development, 67, 3154-3175.

\begin{abstract}
On-line temporal and topic contingencies between child and mother speech are reported at two achievements in language development in the second year. Measured against their respective baseline rates of speech, children were most likely to talk before mother speech and mothers most likely to talk after child speech. This pattern, evident at both language achievements, increased in amplitude with development. These early conversations were generated by the children; neither their interactions nor word learning depended on adult-scaffolding. Only about one third of the children's speech occurred in response to something mothers said; only half of all child speech received a topic-related response. When mothers responded, they most often simply acknowledged, repeated, or clarified what the child said. The results support a model for language development in which children learn language for expression and interpretation in order to share contents of mind, bringing words to their conversations that they've already learned in other contexts.
\end{abstract}

The purpose of the study reported here was to examine children's conversations with caregivers in order to evaluate two alternative models of language development. The first model builds on the Intentionality perspective for explaining language development introduced by L. Bloom (1993a and Bloom and Beckwith, 1989a). In this model, the child's role is primary, and language learning depends more on the mind of the young child and its development than on the conversational skills of an adult in an interaction. The child provides the driving force for conversations and for acquiring language from the beginning of word learning. The second model emphasizes the social context of language use and, in particular, scaffolded linguistic formats constructed by caregivers interacting with young children. This model is built on two main assumptions. The first is that adults control these interactions and provide the structure of the exchange, and the second is that learning language depends on such interactions. In this view, the adult's role is primary for both discourse and language learning.

The two models make fundamentally different predictions about the form and function of early conversations and the relative contributions from children and their caregivers. These predictions were

\footnotetext{
${ }^{1}$ Support for this research was provided by research grants from the National Science Foundation (BSB-8519665), the Spencer Foundation, and Teachers College, Columbia University. We are grateful to the original research team: Richard Beckwith, Joanne Bitetti Capatides, Jeremie Hafitz, and Karin Lifter for helping to create the project and collect and process the longitudinal data. The procedures and formulas for computing baselines for the lag sequential analyses were developed by Richard Beckwith with assistance from Erin Tinker and Adam Meyers and consultation with Karen Clark, James Corter, and Jane Monroe. We thank Pia Rebello, Orly CalderonKlausner, Phyllis Gyamfi, Masako Mori, Marie Simeone, Anna Smith, and Doreen Stanzione, for assistance with data coding. We benefited from conversations about this study with Ira Blake, Lila Braine, Peg Lahey, David Rollock, Bambi Schieffelin, and Stuart Settle. We are particularly indebted to Kathleen Bloom for providing statistical advice, and Joan Lucariello, whose comments on the manuscript helped sharpen the focus and clarify the presentation of the conceptual issues.
} 
tested in this study by examining conversations between mothers and their 1-year-old children in the single-word period of language development.

The scaffolding model was presented most cogently by Bruner (1983a,b) in his description of the social discourse that mothers construct in providing young children with a "language acquisition support system." In accounts of scaffolding, a child's contributions to interactions and to learning are secondary to the "very considerable role" given to the adult (Bruner, 1983b, p. 40). The essentials of the model have been endorsed most notably by Dore (1983), Snow (1977), and Tomasello (1992), among others, who have offered supporting evidence in the same period of early word learning as the study presented here (see Moerk, 1989, for a general review). The evidence for scaffolding has come primarily from studies of interactions in particular situational formats like picture book reading (e.g., Kaye \& Charney, 1980; Ninio \& Bruner, 1978, Snow \& Goldfield, 1983), other routines and games such as "peek-a-boo" (e.g., Ratner \& Bruner, 1978), and scripted play such as a tea party (Kaye \& Charney, 1980). The classic example is the book-reading format from Ninio \& Bruner (1978, pp. 6-7):

Mother: Look! (attentional vocative)

Child: (Touches picture)

M: What are those? (query)

C: (Vocalizes and smiles)

M: Yes, they are rabbits. (feedback and label)

C: (Vocalizes, smiles and looks up at mother)

M: (Laughs) Yes, rabbit. (feedback and label)

C: (Vocalizes, smiles)

M: Yes (Laughs) (feedback)

The function of the mother's contributions to their interactions is to "impose roles, turn taking, joint attention, and a sequential structure" on the interaction. She fits her input to the child's emerging abilities "as fast as the child can manage 'uptake' of her conventions. . . [and] then moves on and embeds these newly established skills into still newer routines, raising the ante when she judges the child to be ready" (Bruner, 1983a, pp. 78, 85). .

The original theoretical model for scaffolding had its roots in Vygotsky (1962) who stressed the importance of what a child first does only with guidance from other persons. This was taken up by Ninio and Bruner (1978) for the case of word learning in language development and by Bruner and others for tutoring and learning more generally. For example, "scaffolding consists essentially of the adult 'controlling' those elements of the task that are initially beyond the learner's capacity, thus permitting him to concentrate upon and complete only those elements that are within his range of competence" (Wood, Bruner, \& Ross, 1976, p. 90). A subsequent source of support for scaffolding came from Vygotsky's extension of his original theory to learning in the "zone of proximal development" (ZPD)-the distance between a child's actual developmental level and the level of potential development possible "under adult guidance or in collaboration with more capable peers" (Vygotsky, 1978, p. 86).

The scaffolding/ZPD account of language learning has been challenged in several ways. First, such contextspecific learning is culturally determined and may well be culture-specific (Ochs \& Schieffelin, 1984). Mothers and children in different cultures and even within the same culture differ in the extent to which they participate in highly structured and conventional routines, games, and joint picture book reading (Camaioni, 1986; Goddard, Durkin, \& Rutter, 1985; Snow \& Goldfield, 1983). In fact, we might question just how much of the learning environment for any child is, indeed, the benevolent context portrayed in psychological studies (Goodnow, 1990), and in accounts of scaffolded conversation.

The asymmetry inherent in scaffolding/ZPD accounts was challenged by Rogoff and others in an effort to "focus on the role of children as active participants in their own development. . . [stressing] the complementary roles of children and caregivers in fostering children's development" (Rogoff, 1990, p. 16). Although acknowledging children's active participation, however, the child was still seen as "guided" in "the sense of direction of the shared endeavor. . . [by] their more mature partners [who] can often more easily find effective ways to achieve shared thinking that stretch the less skilled partner's understanding" (Rogoff, 1993, pp. 134-135). Moreover, while 
considering the agency of the child in participating in an activity, the child was still not seen as an "intentional agent," one who can also reflect on and interpret the activity (Lucariello, 1995).

Language learning occurs when children already know something about the events that inform their activities (Bloom, 1970, 1973). The considerable knowledge about objects, events, and relations in the world that young children bring to their experiences with language provided another challenge to scaffolding/ZPD accounts. The effects of scaffolding interact with, if not actually depend upon what children and their mothers already know about events and other prior knowledge (Lucariello, 1987; Lucariello \& Nelson, 1987).

The main purpose of the study reported here was to show how a model of Intentionality for explaining children's language acquisition provides a better account of children's interactions with caregivers than does the scaffolding model. Intentional states are mental states, representations in consciousness under psychological attitudes of belief, desire, and feeling, and they need to be expressed, made manifest, so other persons can know them (e.g., Danto, 1973, 1983; Searle, 1983; Taylor, 1979, 1985). The Intentionality of a young language-learning child is in the mental representations in consciousness that underlie all the child's actions, including acts of expression and interpretation. These representations determine what children bring to their interactions with other persons and what they learn about language in many different contexts.

Both cognitive and social developments are essential to the Intentionality model of language development (Bloom, 1993a). Cognitive developments are required for constructing the mental representations in consciousness that language can express and that result from interpreting the expressions of others. Social developments are required because the motivation for learning a language in the first place comes from the child's need to share such mental contents for sustaining intersubjectivity with others and establishing the self in a social world.

Three key principles of the Intentionality model for language learning are the principles of relevance, discrepancy, and elaboration-generalizations concerning the contents of mind in relation to the child's context. The principle of relevance narrows the range of possible meanings a word can have: A child will learn words when the target of a word is already part of what the child has in mind. The principle of discrepancy presses the child for expression and interpretation: Developments in the ability to recall past events and anticipate new events create contents of mind that cannot be known from shared perceptions and assumptions and must be expressed or interpreted from the expressions of others. The principle of elaboration presses the child to learn increasingly more of the language: Language must keep up with increasing knowledge about the world as intentional states for expression and interpretation become more elaborated, having more elements with different roles and different relations between roles (Bloom, 1973, 1993a).

From this theoretical perspective, it is a child's inner resources that determine both language learning in general and the process of discourse rather than the external "scaffolding" or "guidance" provided by the more competent partner in an exchange. The child's goal in a conversational exchange is expression and interpretation, to share mental meanings; the partner's goal in the exchange is more to assure the sharing of meaning than to "teach" the child words and more complex syntax. The purpose of this study was to test the fundamentally different predictions which follow from Intentionality and scaffolding models for language development with a finegrained analysis of the behaviors of children and mothers in conversational interactions. Both on-line behaviors in immediate time and developmental changes across time were studied in the period of early word learning in the second year of life.

In a scaffolding model, early word learning occurs in communicative exchanges and depends on an adult or more competent partner to format and frame the interaction, to begin with, and to provide further language models in succeeding turns. For example, Kaye \& Charney (1980) described how mothers of two-year-olds typically built on what a child did or said when responding to the child and attempted to elicit something more on the same topic (what they called "turnarounds"). Half or more of mothers' turns were turnarounds, whereas considerably fewer of their children's turns consisted of such exchanges; they concluded, therefore, that "the dialogue is largely due to the mother" (Kaye \& Charney, p. 220). Thus, we would expect mothers to (1) initiate exchanges to set up the interaction, (2) use more questions than statements when responding in order to "raise the ante" and get the 
child to take another turn, and (3) elaborate on a topic to provide further language models (such as the "extended replies" described by Howe, 1981) rather than simply repeat what the child said.

The Intentionality model leads to a different set of expectations for children's early conversations as potential contexts for word learning. First, if expression of Intentionality is primary, we would expect children to initiate most of their conversational exchanges using words they already know, and their mothers to respond more often to a child's opening turn than to take the first turn. Other research has already shown that mothers are more likely to respond than to initiate conversations (in Harris, 1992, with infants 16 months old and younger, and Howe, 1981, with 20- to 25-month-olds). However, the finding has been attributed to mothers being better at responding than their children are, which discounts the child's part in originating the conversation. Second, when responding in a conversation, we would expect mothers to be more likely to acknowledge what the child had said, to provide assurance that a message was shared, than to press the child to say more or provide more explicit language input for learning. And third, when initiating conversational exchanges, we would expect mothers to make as many or more statements for sharing their own contents of mind than to ask questions in order to begin a format for scaffolding the exchange.

The expectations from the Intentionality model about the form of early conversations would also cast doubt on whether scaffolding is necessary for learning conversational structure. In the pattern of child as initiator/mother as responder, a mother's prompt responding to what her child says maximizes its relevance to what the child has just said and presumably has in mind. Indeed, this pattern is already established with 3-and 4-month-old infants in middle class, white, western societies and their mothers, who take turns while vocalizing and gazing in their prelinguistic interactions (e.g., K. Bloom, 1990; Bruner, 1977; Kaye, 1977, 1979; Newson, 1978; Schaffer, Collis, \& Parsons, 1977; Stern, Jaffe, Beebe, \& Bennett, 1975; Trevarthen, 1977).

The basic synchrony in the patterns of infant and parent vocalizing has been described as "proto-conversation" (Bateson, 1975) and shown to be a statistical analog of the rhythms of adult conversation (Beebe \& Jaffe, 1992; Jaffe, Stern, and Peery, 1973). Most adult responding to prelinguistic vocalizing happens within 1 second after an infant vocalizes (Beebe, Jaffe, Feldstein, Mays, \& Alson, 1985; Roth, 1987; Schaffer et al., 1977). In fact, hearing an adult say something immediately after they have vocalized contributes to the syllabic, conversational quality of 3-month-old infants' vocalizations (K. Bloom, 1977, 1990; K. Bloom, Russell, \& Wassenberg, 1987). Thus, the contingency of the adult's behavior in responding assures conversational turn-taking, but it is the baby's initiating behavior that guides the interaction. Long before language, then, infants show us they can already participate in organized exchanges without words, and the Intentionality model provides a theoretical explanation for these patterned exchanges.

Scaffolding would seem to be necessary for learning to participate in conversations only if the earlier developments of infancy are discontinuous with developments in the second year when words begin to appear. The period of early word learning intervenes developmentally between prelinguistic turn-taking without words in the first year and later discourse contingency with sentences that develops in the third year as children acquire a grammar (Bloom, Rocissano, \& Hood, 1976; Shatz, 1983). This intervening period provides an opportunity to examine continuity with later developments in conversation as well as the earlier developments of infancy. The period begins with first words, at around the first birthday, and continues until the acquisition of a vocabulary of some time toward the end of the second year.

\section{METHODS}

This research was part of a larger study of language acquisition in which a group of 12 children was studied longitudinally from 9 months to 2 years of age, and two achievements in vocabulary acquisition were identified, one at the beginning and another at the end, of the single-word period. These two achievements-first words and a vocabulary spurt-were used as reference points for equating the children on the basis of their language rather than age, in order to determine relations between language acquisition and other aspects of their development (Bloom, 1993a). The focus in the present study was on features of temporal and topic contingency in the conversations between the children and their mothers in the same period. 


\section{The Children}

The children were 6 girls and 6 boys, all first-born, whose mothers were their primary caregivers throughout the period of study. The children and their mothers came from families who lived in the New York metropolitan area and differed in ethnic, racial, economic, and religious backgrounds. Eight children were Euro-American; 2 were African-American; 1 was mixed African-American and Puerto Rican Hispanic; and 1 was mixed Dominican Hispanic, Euro-American, and Native American. These last 4 children were also from the poorest families in our sample (with incomes less than $\$ 10,000$ in 1982), reflecting the fact that ethnicity and poverty are often coextensive in urban communities like New York. Except for non-English kin terms, for example, Hebrew "Aba" and "Ema" and occasional words like "agua" and "mira!," American English and the African English vernacular were spoken in their homes. The children were seen every month, beginning at 9 months of age and continuing until they were saying simple sentences with mean length of utterance greater than 1.5 words (mean age $=23$ months 7 days). (See Bloom, 1993a, for further description of the children and procedures.)

\section{Data Collection and Processing}

The monthly observation sessions were video-recorded in a playroom at Teachers College, Columbia University, and these sessions provided the primary data we used for our studies. In addition, the mothers kept diaries of the words their children said and understood at home, and we visited the children and video-recorded their interactions at home every month until they were 15 months old and every 3 months thereafter. The home visits gave confidence that the interactions we observed in the playroom were consistent with how the mothers and infants interacted in their homes. The same pair of research assistants was responsible for collecting the data in the playroom and in the home visits; they were also in touch by telephone with the mothers in the weeks between sessions to encourage their diary-keeping; research assistants and subjects were matched for race.

The mothers were asked to interact with their infants in the playroom as they ordinarily would at home. The room was equipped with a child-size table and 2 chairs, a 3-foot plastic slide with a crawl space, and a changing table. A group of toys was on the floor when the infant and mother came into the playroom, and other groups of toys were brought in every 8 minutes according to a schedule. A snack instead of a new group of toys was provided after the first half-hour. The same toys with the intervening snack were presented every month, on the same schedule, to all the children. This consistency in the situation in which we observed them meant that change in the interactions between mother and child over time could be attributed to development and learning, and differences between the mother-child pairs could be attributed to inherent differences among them rather than to the context of their interactions.

Data were video recorded using a Sony SLO-383 half-inch stereo Betamax interfaced with a FOR-A 3500 SMPTE time code generator. The computer-readable time code was a discrete audio signal recorded every 1/30th second on the tape to mark 30 frames per second of interaction. At the time of data processing, the video deck was interfaced with an Apple II plus microprocessor via a time code reader for coding and transcription (See Beckwith, Bloom, Albury, Raqib, \& Booth, 1985; Bloom, 1993b). Every transcription and coding decision was associated with times of the behavior onset and offset. The time code associated with the separate behaviors made it possible for the computer to subsequently integrate them, for example, the child and adult speech, to restore their original temporal sequence. The database that now exists, as a result of several studies of these children's development, is richly contextualized, with integrated records of, among other things, children's speech, affect expression, and object play in relation to mothers' speech, behaviors around the children's emotional expressions, and description of the situations that accompanied mothers' sentences (see, for example, Beckwith, 1988; Bloom \& Beckwith, 1989b; Bloom \& Capatides, 1987; Capatides, 1990; Lifter \& Bloom, 1989).

\section{Equating the Children for Language Development}

Because of well-known differences in age of onset and rate of language acquisition, two achievements in word learning were identified to equate the children for onset and level of language development: first words (FW) and a vocabulary spurt (VS). FW was the first occurrence of at least one phonetically consistent, meaningful, conventional word used at least 2 different times in a playroom session. The acquisition of new words was tracked from month to month in the playroom, and a vocabulary spurt was identified when the number of new words in a session showed an increase equivalent to at least 3 new words per week, or 12 new words over the preceding 
month, after the child had already learned at least 20 different words. All the children showed a vocabulary spurt given these criteria. ${ }^{2}$

Mean ages for the children at FW and VS, respectively, were 13 months 18 days (range $=10$ months 5 days to 17 months), and 19 months 18 days (range $=13$ months 2 days to 25 months 5 days). The mean number of word types in the children's playroom vocabularies was 4.43 at FW (range $=2-12$ ) and 50.8 at VS (range $=34-75$ ). We were confident we had captured the rate of vocabulary growth through our monthly sampling because the children's mean ages at 10 words and then at 50 words in the playroom were, respectively, 15 mos, 14 days and 19 mos, 24 days--virtually the same ages reported in other studies based on mothers' diary data (e.g., Menyuk, Liebergott, Schultz, Chesnick, \& Ferrier, 1991; Nelson, 1973). The VS reference point we identified for achievement in word learning happened to coincide with the children's achievement of a commonly used landmark in the literature: All the children reached a 50-word vocabulary within 1 month of the month in which they met the criteria for a vocabulary spurt (either in the same month or 1 month before or after).

This study departed from many previous studies of mother and child conversations in that only intelligible speech was counted as turns. Nonlinguistic behaviors like other vocalizations, gestures, actions, and emotional expressions were not counted as turns by themselves. Other studies of communicative interactions in the same age range have typically treated actions and other non-word responses as turns in order to maintain consistency with studies of interaction in infancy before speech begins (e.g., Chapman, Miller, MacKenzie, \& Bedrosian, 1981; Foster, 1986; Harris, 1992; Kaye \& Charney, 1980; Snow, 1977). Such nonlinguistic behavior certainly contributes to social interaction in important ways. However, the focus of this study was on developments in conversation, and definitions of conversation specifically require "naturally occurring spoken language" (Crystal, 1987, p. 116).

\section{Contingency Analyses}

The data were analyzed to determine the on-line patterns of temporal contingency between child and mother speaking, the extent and kind of topic sharing between their adjacent messages, and developments in temporal and topic contingency from FW to VS.

Temporal Contingency. We looked first at the temporal contingencies (i.e., sequencing in real time) between child and mother speech in the first half-hour of the FW and VS observation sessions, using a form of lag sequential analysis (Bakeman, 1978; Sackett, 1974, 1979). In the first analysis, child speech was the target event and the incidence of mother speech around the target was determined in the following way. The computer located each instance of child speech and then scanned 15 seconds before its onset time, the time interval of child speech between onset and offset, and 15 seconds after offset of child speech to determine if mother speech occurred at the same time the child was speaking or in any of the 151-s intervals before and after. The incidence of a mother's speech was then computed as a percentage of the number of child-speech targets for which her speech occurred in any of the 1-s intervals before and after.

The incidence of mother speech during the target interval itself was treated differently because the duration of the child's speech, from onset to offset times, could have been longer or shorter than the preceding and following 1-s intervals. The likelihood that mother speech would occur during child speech was, therefore, confounded by the duration of the child speech: Mother speech would be more likely to occur during child speech lasting more than 1 second than in any of the lags preceding or following just because the child speech happened to be longer than $1 \mathrm{sec}$. Conversely, the mother's speech would be less likely to occur during child speech lasting less than 1 second than in the other lag intervals before and after. The program corrected for this confound by computing the actual percentage of target frames in which mother and child speech occurred simultaneously.

\footnotetext{
2 The criteria for VS were not arbitrary; they were the parameters that characterized a change in the slope of the vocabulary growth curves of the 3 children who had provided the pilot data for the larger study (in Lifter, 1982). Mother reports based on diaries or checklists do not always reveal a marked change in slope for rate of word learning (e.g., Goldfield \& Reznick, 1990; but see Mervis \& Bertrand, 1995, for a dissenting account). The children in this study varied both in vocabulary size at VS and the slope of the growth curve between FW and VS (the individual growth curves can be seen in Bloom, 1993a).
} 
The incidence of a mother's speech before, during, and after her child's speech was then compared to her baseline rate of speaking: the chance probability of her speaking given how much speaking she did throughout the observation. Thus, the baseline represented the incidence of mother speech overall, as it was distributed throughout the entire 30-minute observation, rather than only in the seconds preceding and following the target behaviors. The baseline for the 1-s lag intervals before and after child speech was computed using a procedure comparable to the method used to obtain the observed incidence of mother speech in the 1-s intervals before and after child speech. This baseline was the likelihood that mother speech would occur in any 1-s interval in the observation-in effect, the percentage of all 1,800 1-s intervals in the first half hour of the observation that occurred with speech-and the standard deviation was its estimated variance. The baseline for the target interval, the duration of which varied by frames (with 30 frames per second), was the likelihood that mother speech would occur during any frame in the observation and was computed as a percentage of all the frames in the half-hour observation in which speech occurred. Derived z-scores were then computed as differences from these respective baselines in standard deviation units. The derived z-score was the mean percent of speech in an interval minus the baseline divided by the standard deviation.

In an ad hoc analysis, we compared results using the same baseline rate for both the targets and the 1-s intervals before and after. When child-speech targets were treated as a constant, z-scores for targets with an average duration less than 1 second were lower than the z-scores obtained with the target length treated as variable. This was because mother speech was less likely to occur during intervals less than 1 second long. For child-speech targets with an average duration longer than $1 \mathrm{sec}$, z-scores were higher when the targets were treated the same as the preceding and following 1 second lags only because a mother's speech was more likely to occur during intervals longer than $1 \mathrm{sec}$. These results confirmed that we were making the correct adjustment for the variable duration of target events.

The same procedure was repeated in the second analysis, this time using mother speech as the target event to determine the incidence of child speech relative to the child's baseline rate of talking during mother speech and in the 151 -s intervals before and after. Thus, the results for temporal contingency consisted of the on-line relationships in real time between mother and child speech in relation to their respective baseline rates of speaking at two times in the children's language development, FW and VS. The results at FW and VS were then compared for changes in temporal contingency with developments over time in word learning.

The resulting on-line temporal patterns of child and mother speaking showed that the critical deviations from their respective baseline rates clustered around the target behaviors. For this reason, the statistical analysis of the data focused on 3 intervals for child and mother speech: the target, the 1 second before the target, and the 1 second after. The z-scores in these intervals were submitted to fully repeated measures analyses of variance, with both time relative to the target $\mathrm{T}$ : $\mathrm{T}-1, \mathrm{~T}, \mathrm{~T}+1$, and language achievement: $\mathrm{FW}, \mathrm{VS}$, as within subject variables.

Topic Contingency. Perspective sharing between infants and caregivers is eventually accomplished through linguistic devices like pronoun shifting, rising intonation, and tag questions. However, before such devices are acquired, perspective sharing is evident when adult and child talk about the same topic (Bloom, Rocissano, \& Hood, 1976; Keenan \& Schieffelin, 1976). The analysis of shared topic made use of results from two coding schemes devised in the context of other research, a code for the intentional state representations attributed to the children's word and affect expressions (Bloom, Beckwith, Capatides, \& Hafitz, 1988), and a code for the situation in which mothers' sentences occurred (Beckwith, 1988). The child Intentionality code was an attribution of the persons, objects, and actions in the child's focus of attention and whether the expression was a desire (to change the world) or a belief (in the way the world appeared to be). The mother sentence-situation code identified causes, entities, states, actions, and the relations between these elements in the situation. The child Intentionality code and the mother sentence-situation code were applied to the data independently of each other, and independently of the purposes of the study reported here. Together with mother and child speech, the results of these coding schemes yielded a richly contextualized transcription of speech events for determining whether child and mother speech shared the same topic.

The results of the lag sequential analyses revealed that mother and child most often talked within 2 seconds of each other. For this reason, 2 seconds was the window used to define adjacency of mother and child speech; all 
pairs of adjacent turns within a 2-s window were then examined to determine if they shared the same topic and if so, the form and function of utterances. Thus, child speech in mother $\rightarrow$ child adjacency pairs was examined to determine whether the children shared the mother's topic either by repeating part of the mother utterance or saying something different but related to it (child topic sharing). Correspondingly, mother speech in child $\rightarrow$ mother adjacency pairs was examined to determine whether mothers shared the child's topic (mother topic sharing), and mother speech that shared the child's topic was coded for its form and function relative to the child utterance.

The form of mothers' speech in both mother $\rightarrow$ child and child $\rightarrow$ mother sequences was coded as question or statement, and also coded as a repetition if all or part of a child's preceding utterance was repeated. The first of 2 categories of function was action-related, with 2 subcategories according to whether the mother encouraged the child to act in some way or discouraged the child's acting. The second category of function was discourserelated, with the subcategories: acknowledgment, clarification, encouragement to say something, and description/assessment (this last subcategory is consistent with the criteria used by Howe, 1981, who defined "conversation" as an exchange of information). The categories for coding mother speech are given in the appendix. Child topic sharing responses were compared after mother questions and statements, and after mother action- and discourse-related speech.

\section{Extended Conversations}

Topic sharing that extended beyond the 2-turn adjacency pairs was examined to determine the frequency of extended conversations. This analysis consisted of first identifying sequences with at least 3 alternating child and mother speech turns that shared the same topic, and then describing these conversations in terms of who initiated the sequence, who ended it, and the number of turns in the sequence.

Two or more successive utterances by the same speaker were considered a single turn when they occurred within 2 seconds (from the offset time of the first utterance to the onset time of the last). A conversational sequence was considered to have ended when more than 5 seconds elapsed between 2 turns by the same or different speakers (from the offset time of the first turn to the onset time of the second turn). This second criterion was adopted to avoid counting as a conversational sequence a succession of utterances tied to moves in an activity (such as stacking blocks or doing a puzzle), where speech was contingent on the action and the context rather than on the speech of the interactants. In fact, this rule was required infrequently when coding the data, and we were confident that topic sharing after 5 seconds was rare.

\section{Reliability}

Speech Transcription. Child speech and mother speech were each transcribed independently by different persons who were unaware of the purposes of the present study. The first transcription was a handwritten record that was then verified by a second transcriber who entered the data into the computer with times of speech onset and offset. The computer record was then reviewed by both transcribers together to resolve any disagreements between the two transcription passes; if agreement was not reached, the data were entered in phonetic notation as a non-word and not used in the analyses. Subsequently, approximately 3-5 years later, all the transcriptions were reviewed again by two independent transcribers who verified and edited the computer entries for subsequent research (e.g., Bloom, Tinker, \& Margulis, 1993). The average margin of error among coders for coding speech onset and offset (after extensive training) was remarkably small: within 2 video frames (or 1/15 $\mathrm{sec}$ ) for word onset time and within 5 video frames (or 1/6 sec) for word offset (Bloom \& Capatides, 1987).

Temporal Contingency. The reliability of the computer program for the lag sequential analysis to determine temporal contingency was established by comparing the results of the program with hand counts based on the hard copy transcriptions of 2 children's VS observations. The occurrence of a lagged variable (for example, mother speech) was counted in the time interval between the onset and offset times of targets (for example, child speech) and in the 15 1-s intervals before a target onset time and the 151-s intervals after the target offset time. The two observations included mother speech, child speech, and child affect expression (used for other studies) as lagged variables for each of 447 child speech targets, 414 mother speech targets, and 78 object play targets (also for a different study), for a total of 29,109 intervals. The transcription count was compared with the counts produced by the computer program until 100 per cent agreement between them was reached. 
Topic-Related Speech. First, validity was established for using the transcriptions of child and mother speech with context provided by information from the two prior codes for intentional state and situation. This was done by comparing the results of coding topic sharing and the functions of mother speech from the transcriptions with the results of coding directly from the video observations of 2 of the children at VS. Two coders worked independently. One coded 70 consecutive adjacency pairs directly from one videotaped observation, and the other coded 70 pairs from the second to determine whether successive utterances in a pair shared the same topic. Their coding decisions from the video tapes were then compared with the coding decisions made from the 2 respective transcriptions, each of which was coded by the other person, to determine the validity of using the two source codes for intentional state and situation as context for coding topic sharing. The result was 97.1\% agreement on topic sharing between coding the tape and transcript for one comparison (Kappa $=.922)$ and 95.7\% agreement for the other (Kappa $=.905)$.

Validity was then established for coding the function of mother's speech given that the topic was shared. Eliminating those adjacency pairs that either did not share topic or were not agreed upon resulted in 52 remaining pairs from one observation and 47 remaining pairs from the other for coding function. Comparing coding decisions from the video tapes and transcripts yielded $92.3 \%$ agreement on function for one comparison and 95.7\% agreement for the other. (Cohen's Kappa was not appropriate for comparing percent agreement on functions with chance agreement because of the large number of coding fields, as many as 7 decisions for each utterance, which yielded too few data points in cells; see Howell, 1992).

Reliability for coding the transcriptions was then established by independently coding 2 transcriptions for topic sharing and function of mothers' speech. In all, 94 adjacency pairs, 30 from one transcription and 64 from the other, were coded independently to determine whether successive utterances in each pair shared the same topic. Agreement between the two coded transcriptions for the 94 adjacency pairs was 92.6\% for topic sharing (Kappa $=.812$ ). Then, eliminating those adjacency pairs that either did not share the topic or were not agreed upon resulted in 65 remaining pairs for coding agreement of function. Comparing the coding decisions yielded 95.4\% agreement on function. In all, 234 adjacency pairs were used for determining validity/reliability, which represented $16.8 \%$ of all the adjacency pairs in the data from all the children. Finally, the form of mothers' speech was either a question or a statement, and could also be coded as repetition if part or all of the child's utterance was repeated; coding the form of mother speech was straightforward, with virtually no disagreements between coders.

Together, the findings from the analyses in this study provided an account of the form and function of true conversations between mother and child interactants in the period of early word learning, and an opportunity to test whether developments in progressing from first words to the vocabulary spurt could be attributed to the patterns of conversational interaction.

\section{RESULTS}

\section{Temporal Discourse Contingency}

The data from the lag sequential analyses are presented in Tables 1 and 2 for FW and VS, respectively. Because of deterioration in the equipment after 10 years of data processing, the time stamp at FW for one child (who said 2 words at FW) could not be read for the analysis; thus, the data in Table 1 and analysis of variance results for the interaction between FW and VS came from 11 children. The information in Tables 1 and 2 includes the number of target events, the child and mother percent baseline rates of talking for both targets and 1-s lags before and after the targets, and the percentages of targets in which child and mother speech occurred during the targets $(\mathrm{M}$ or C), 1 second before (-1), and 1 second after $(+1)$. The percentages of child speech were quite low, particularly at FW, while the percentage of time the mothers were talking was relatively high, as can be seen from their respective baselines. For example, the child Ro had a baseline of .4\% for the 1-s lag intervals at FW (Table 1), meaning that speech occurred in less than $1 \%$ of all the 1-s intervals in the observation; his mother had a baseline of $26.8 \%$, meaning that she talked in about one fourth of all the 1-s lag intervals in the observation. 
Table 1. The Number of Target Events, Child and Mother \% Baseline Rates of Speaking, and the Incidence (\% Of Targets) of Child and Mother Speech During the Targets, 1 Second Before, and 1 Second After, at FW

\begin{tabular}{|c|c|c|c|c|c|c|c|c|c|c|c|c|}
\hline \multirow[b]{3}{*}{ Child } & \multirow{2}{*}{\multicolumn{2}{|c|}{ TOTAL TARGETS }} & \multirow{2}{*}{\multicolumn{2}{|c|}{$\begin{array}{c}\text { CHILD } \\
\text { BASELINES }\end{array}$}} & \multirow{2}{*}{\multicolumn{2}{|c|}{$\begin{array}{c}\text { MOTHER } \\
\text { BASELINES }\end{array}$}} & \multicolumn{6}{|c|}{$\%$ OF TARGETS } \\
\hline & & & & & & & \multicolumn{3}{|c|}{ Child Speech } & \multicolumn{3}{|c|}{ Mother Speech } \\
\hline & Child & Mother & Lag & Target & Lag & Target & -1 & M & +1 & -1 & $\mathrm{C}$ & +1 \\
\hline Sh,f . & 2 & 541 & .2 & .1 & 56.3 & 34.5 & .2 & 0 & 0 & 50.0 & 0 & 100 \\
\hline Co,f ............... & 17 & 259 & 1.7 & 6 & 24.0 & 10.8 & 2.3 & 0 & .8 & 5.9 & 0 & 29.4 \\
\hline $\mathrm{Gr}, \mathrm{f} \ldots \ldots \ldots \ldots$ & 3 & 359 & .4 & .5 & 31.7 & 15.3 & .6 & 0 & 0 & 0 & 0 & 33.3 \\
\hline Di,f .............. & 9 & 222 & .9 & .4 & 18.9 & 9.5 & .5 & 0 & .5 & 11.1 & 0 & 11.1 \\
\hline Ro,m ............ & 12 & 361 & 1.0 & .4 & 42.0 & 26.8 & 2.2 & .2 & .3 & 16.7 & 16.2 & 66.7 \\
\hline $\mathrm{Vi}, \mathrm{f} \ldots \ldots \ldots \ldots$ & 13 & 456 & 1.2 & .5 & 52.5 & 33.3 & 2.4 & .4 & 2.4 & 84.6 & 13.8 & 76.9 \\
\hline $\mathrm{Al}, \mathrm{m} \ldots \ldots \ldots$ & 1 & 404 & .05 & .04 & 32.4 & 14.9 & .2 & 0 & .2 & 100 & 0 & 100 \\
\hline 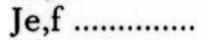 & 9 & 220 & .5 & 1.0 & 21.0 & 10.6 & 1.8 & .5 & .5 & 11.1 & 6.6 & 33.3 \\
\hline $\mathrm{Cl}, \mathrm{m} \ldots \ldots \ldots$ & 6 & 176 & 6 & .2 & 18.9 & 9.5 & 1.1 & 0 & .6 & 16.7 & 0 & 33.3 \\
\hline Re,m ............ & 3 & 87 & .3 & .1 & 8.0 & 4.0 & 1.1 & 0 & 0 & 0 & 0 & 33.3 \\
\hline Ch.m ........... & 30 & 464 & 3.0 & 1.6 & 49.6 & 28.1 & 5.0 & 1.1 & 4.1 & 63.3 & 15.2 & 63.3 \\
\hline
\end{tabular}

Note. The children are listed by the first two letters of their pseudonyms in order of their chronological ages at the time of FW, from youngest to oldest, with gender indicated as " $\mathrm{f}$ " or " $\mathrm{m}$." The incidence of child and mother speech is the mean percent of the number of targets events with speech occurring before, during, or after the target. Lag baselines are the percent of all 1-s intervals in the observation in which speech occurred; target baselines are the percent of speech in all framers of the observation ( 1 frame $=1 / 30 \mathrm{~s}$ ).

The children are listed in the tables in order of their chronological ages at FW and VS, respectively. Chronological age was not correlated with the total number of child or mother target events at either time; none of the correlations approached significance. This means that how frequently the children and mothers talked could be attributed with some confidence to their progress in language rather than age alone.

Table 2. The Number of Target Events, Child and Mother \% Baseline Rates of Speaking, and the Incidence (\% Of Targets) of Child and Mother Speech During the Targets, 1 Second Before, and 1 Second After, at VS

\begin{tabular}{|c|c|c|c|c|c|c|c|c|c|c|c|c|}
\hline \multirow[b]{3}{*}{ ChILD } & \multirow{2}{*}{\multicolumn{2}{|c|}{ TOTAL TAFGeTS }} & \multirow{2}{*}{\multicolumn{2}{|c|}{$\begin{array}{c}\text { CHILD } \\
\text { BASELINES }\end{array}$}} & \multirow{2}{*}{\multicolumn{2}{|c|}{$\begin{array}{l}\text { MO'THEF } \\
\text { BASELINES }\end{array}$}} & \multicolumn{6}{|c|}{ OF TAKGETS } \\
\hline & & & & & & & \multicolumn{3}{|c|}{ Child Speech } & \multicolumn{3}{|c|}{ Mother Speceh } \\
\hline & Child & Mother & Lag & Target & Lag & Target & -1 & $\mathrm{M}$ & +1 & -1 & $\mathrm{C}$ & +1 \\
\hline Sh,f $\ldots \ldots \ldots \ldots$ & 135 & $\mathbf{5 7 9}$ & 117 & 4.5 & 60.6 & 35.0 & 18.1 & 1.0 & 10.0 & 43.7 & 6.4 & 77.8 \\
\hline$V$ i,f ................. & 57 & 514 & 62 & 3.0 & 49.0 & 27.6 & 8.4 & 1.3 & 6.4 & 52.6 & 10.3 & 63.2 \\
\hline $\mathrm{Co}, \mathrm{f} \ldots \ldots \ldots \ldots$ & 90 & 396 & 9.9 & 6.3 & 39.5 & 22.3 & 17.2 & 2.6 & 8.3 & 37.8 & 8.7 & 73.3 \\
\hline $\mathrm{Cl}, \mathrm{m}$ & 87 & 216 & 8.3 & 3.8 & 23.9 & 12.7 & 16.2 & .5 & 6.0 & 18.4 & 2.9 & 42.5 \\
\hline 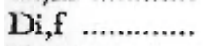 & 51 & 225 & 4.3 & 1.9 & 23.4 & 13.4 & 9.8 & 2.3 & 5.8 & 35.3 & 17.2 & 54.9 \\
\hline $\mathrm{Ha}, \mathrm{m}$ & 69 & 513 & 6.6 & 3.1 & 47.3 & 28.7 & 13.3 & 2.9 & 9.2 & 62.3 & 25.5 & 84.1 \\
\hline Ro,m .......... & 78 & 470 & 7.1 & 2.7 & 40.9 & 19.9 & 14.9 & .6 & 10.9 & 61.5 & 2.9 & 80.8 \\
\hline Ch,m ............... & 119 & 454 & 11.7 & 5.1 & 47.6 & 27.5 & 19.4 & 1.5 & 13.2 & 48.7 & 7.0 & 63.9 \\
\hline $\mathrm{Gr}, \mathrm{f} \quad \ldots \ldots \ldots \ldots$ & 136 & 559 & 14.8 & 7.7 & 55.8 & 32.8 & 20.0 & 4.6 & 13.6 & 54.4 & 18.6 & 70.6 \\
\hline $\mathrm{A}], \mathrm{m}$ & 31 & 282 & 3.2 & 1.8 & 28.7 & 16.3 & 5.7 & .4 & 3.9 & 35.5 & 5.8 & 51.6 \\
\hline Re,m .............. & 86 & 69 & 8.3 & 4.3 & 6.8 & 3.3 & 20.3 & 3.2 & 15.9 & 12.8 & 2.7 & 16.3 \\
\hline Ie,f $f \ldots \ldots \ldots \ldots$ & 176 & 414 & 16.1 & 6.7 & 39.8 & 18.7 & 23.9 & 2.2 & 22.2 & 56.8 & 5.0 & 62.5 \\
\hline
\end{tabular}

Note. The children are listed by the first two letters of their pseudonyms in order of their chronological ages at the time of VS, from youngest to oldest, with gender indicated as " $\mathrm{f}$ " or " $\mathrm{m}$." The incidence of child and mother speech is the mean percent of the number of targets events with speech occurring before, during, or after the target. Lag baselines are the percent of all 1-s intervals in the observation in which speech occurred; target baselines are the percent of speech in all framers of the observation ( 1 frame $=1 / 30 \mathrm{~s}$ ).

Comparing the incidence of mother and child speech to their respective baselines (how much they talked, in general, in these sessions), verified that the speech of one tended to cluster around the speech of the other. However, this cannot be seen in the tables, because neither the comparisons between baselines and observed speech in the intervals around targets nor the data for the remaining 28 intervals before and after the targets are 
shown. Accordingly, the patterns that resulted from the analyses are shown in Figures 1 and 2; for the sake of economy, data are presented in the figures the for just the 51 -s intervals before and after the target events.

\section{Mothers' Speech Around Children's Words}

Mothers' tendency to talk before, during (at C), and after their children said something is shown in Figure 1 as the means of their $z$-scores relative to baseline at FW and VS. Mothers were more like each other at FW and much closer to baseline rates of talking in general than they were at VS. The mothers were more variable in their profiles of talking at VS. Nevertheless, all the mothers showed the same profile as the group, with more speech after than before and the least likelihood of talking at the same time their children were talking.

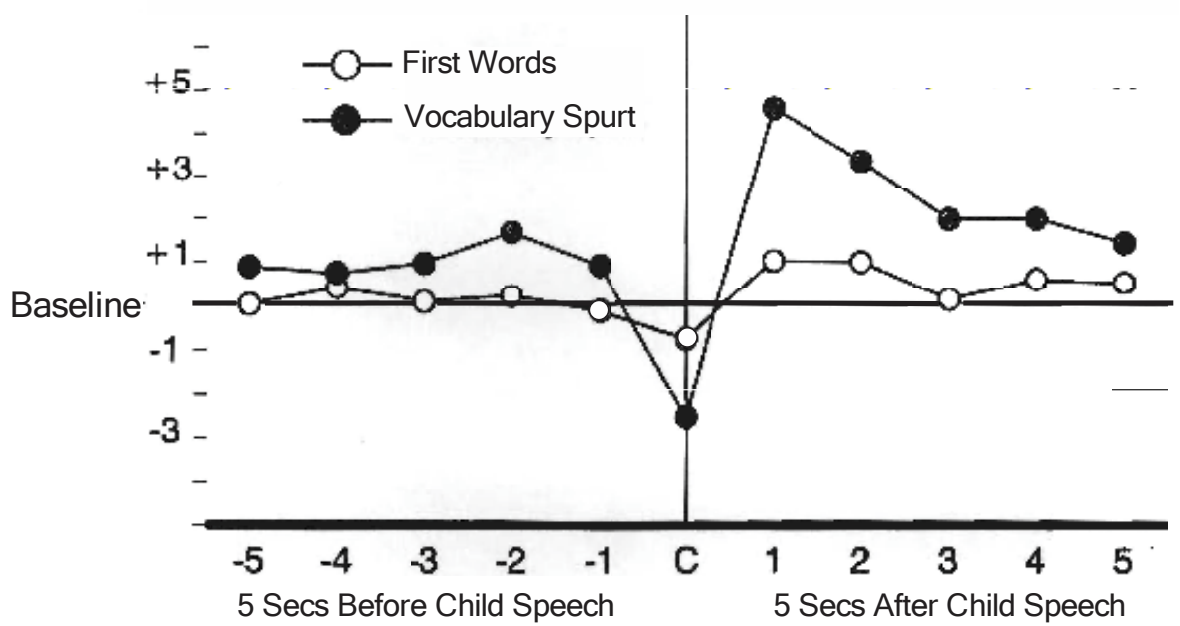

Figure 1. Mean $z$ scores (in SD units) of mothers' speech around children's speech (C) relative to baseline rates of mothers' speech at FW and VS $(n=11)$

The temporal contingencies in Figure 1 were tested statistically using the scores for the 3 central data points: C, the interval in which the children's speech occurred; $\mathrm{C}-1$, the 1 second interval immediately before the children's words; and $\mathrm{C}+1$, the 1 second immediately after. The results were confirmed by a 3 (time: $\mathrm{C}-1, \mathrm{C}, \mathrm{C}+1$ ) by 2 (language achievement: FW, VS) fully repeated measures analysis of variance based on the 11 children for whom data were available at both FW and VS. The overall deviation from baseline for mother talking (the mean of the scores in the 3 intervals at each level) was not different at FW and VS, F $(1,10)=1.84, p=.204$. However, the degree to which mothers deviated from their baseline rates of talking was different across the 3 intervals encompassing children's words, with a main effect for time, $\mathrm{F}(2,20)=58.90, p<.001$. And the excursions from baseline were greater at VS than at FW, with an interaction of time and level, $\mathrm{F}(2,20)=22.41, p<.001$. Thus, the patterns of on-line temporal relationship between mothers' speech and their children's words were the same at both language achievements, but much greater in amplitude at VS, confirming the result in Figure 1.

The patterns of temporal differences from baseline in mothers' speech around children's words were tested separately at FW and VS, given the significant interaction between them, with one-way repeated measures analysis of variance. At FW, the effect of time was significant, $\mathrm{F}(2,20)=13.28, p<.001$. The trend analyses revealed that the pattern was explained as a quadratic curve, $t(10)=4.0701, p=.002$, which accounted for $61.1 \%$ of the variance, and was attributable to mothers' being least likely to talk at $\mathrm{C}$. There was also a significant linear trend from $\mathrm{C}-1$ to $\mathrm{C}+1, t(10)=3.1268, p=.011$, accounting for $36.6 \%$ of the variance. Mothers were more likely to be talking at $\mathrm{C}+1$ than at either $\mathrm{C}, t(10)=7.23, p<.001$ or $\mathrm{C}-1, t(10)=-3.13, \mathrm{p}=.011$ (mother talk at $\mathrm{C}-1$ was not different from talk at $\mathrm{C}, t(10)=1.65, \mathrm{p}=.130$ ). The one-way repeated measures analysis was performed with only the data from those children with 3 or more targets at FW $(n=9)$. The deviations from baseline from C-1 through $\mathrm{C}$ to $\mathrm{C}+1$ continued to be significant, $\mathrm{F}(2,16)=9.17, p=.002$.

The same pattern was obtained at VS. The effect of time was significant, $\mathrm{F}(2,20)=48.12, p<.001$, with the trend analyses revealing that the pattern was again explained as a quadratic curve, $t(10)=7.7459, p<.001$, accounting 
for $62.4 \%$ of the variance, with a significant linear trend from $\mathrm{C}-1$ to $\mathrm{C}+1, t(10)=5.4457, p<.001$, accounting for $30.8 \%$ of the variance. At VS, mothers were more likely to be talking relative to baseline at $\mathrm{C}+1$ than at either $\mathrm{C}$, $t(10)=8.81, p<.001$ or $\mathrm{C}-1, t(10)=-5.45, p<.001$. In addition at VS, mothers were more likely to be talking relative to baseline at $\mathrm{C}-1$ than at $\mathrm{C}, \mathrm{t}(10)=5.05, p=.001$. When the one way repeated measures analysis of variance was performed with 12 children, to include the mother and child from whom data were also available at VS, the effect of time continued to be significant, $\mathrm{F}(2,22)=56.39, p<.001$.

When comparing FW and VS, mothers were much more responsive to their children's talking at VS. At VS, they talked more, relative to baseline, immediately after their children said something $($ at $\mathrm{C}+1)$, than at FW, $t(10)=-$ $5.78, p<.001$, and talked less, relative to baseline, at the same time (at C), $t(10)=3.43, p=.006$. The difference between FW and VS in mothers' talking just before a child spoke (C-1) was not significant, $t(10)=-1.00 p=.340$.

In sum, the basic pattern of turn-taking was already evident at FW: Mothers were most likely to talk immediately after their children said words, and they were least likely to be talking at the same time. This pattern was consolidated at VS with a statistically reliable increase in amplitude in the shape of the curve of mothers' speech around children's words.

\section{Children's Words Around Mothers' Speech}

The children's tendency to talk at the same time their mothers were talking and in the seconds before and after, is shown in Figure 2 as the means of the z-scores for the group relative to baseline at FW and VS. Child speech peaked above baseline levels in the 1 second immediately before mothers' speech, and the children were more likely to be talking before their mothers said something (M-1) than they were afterwards $(M+1)$ or at the same time (at M). These results mirrored those reported for the mothers who were most likely to be talking immediately after their children said words.

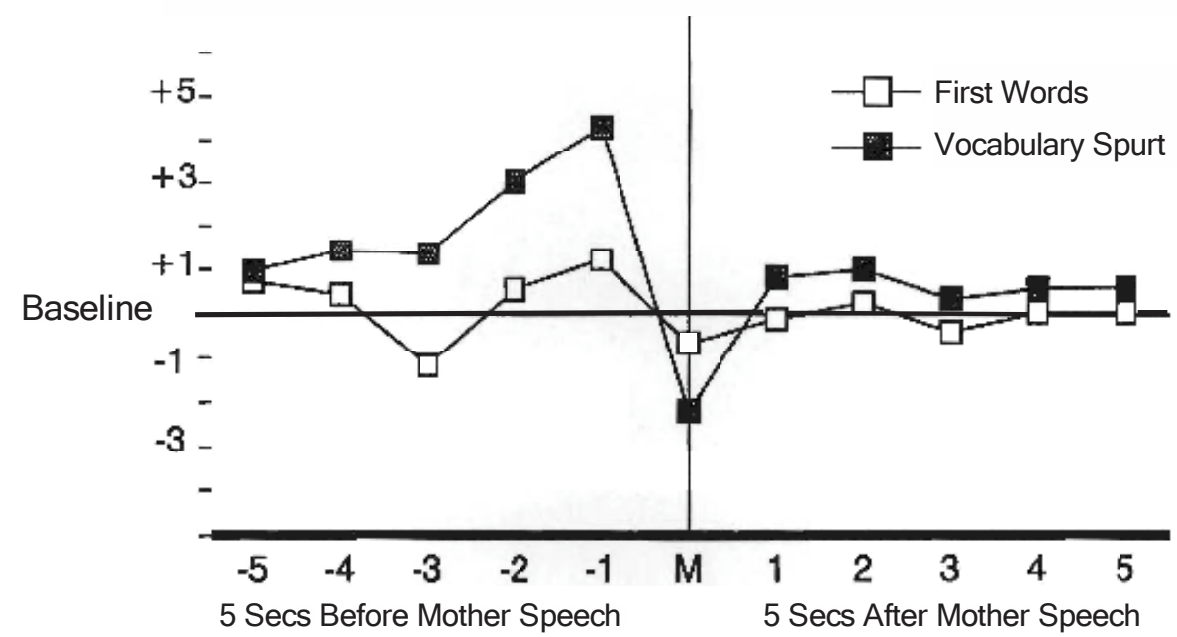

Figure 2. Mean $z$ scores (in SD units) of children's speech around mothers' speech (M) relative to baseline rates of children's speech at FW and VS $(n=11)$

The results in Figure 2, with the 11 children for whom data were available at FW, were confirmed by a 3 (time: $\mathrm{M}-1, \mathrm{M}, \mathrm{M}+1$ ) by 2 (language achievement: FW, VS) fully repeated measures analysis of variance. The overall deviation from baseline for children talking around mother speech (the mean of the scores in the 3 intervals at each level) was not different at FW and VS, F $(1,10)=3.34, \mathrm{p}=.097$. However, the degree to which the children deviated from their baseline rates of talking differed across the three intervals encompassing mothers' speech, with a significant main effect for time, $\mathrm{F}(2,20)=72.88, p<.001$. Moreover, the excursions from baseline were greater at VS than at FW, with an interaction of time and level, $\mathrm{F}(2,20)=22.70, p<.001$. Again, as with the online temporal pattern of mother speech around child speech, the patterns of child speech around mother speech were the same at both language achievements but much greater in amplitude at VS. 
The patterns of change from baseline in the children's talk around mothers' speech were tested separately at FW and VS, given the significant interaction between them, with one-way repeated measures analyses of variance. At FW, the effect of time was significant, $\mathrm{F}(2,20)=16.23, p<.001$. The results of trend analyses revealed that the pattern was explained as a quadratic curve, $t(10)=4.2041, p>.002$ which accounted for $54.4 \%$ of the variance, with a significant linear trend from $\mathrm{M}-1$ to $\mathrm{M}+1, t(10)=-3.8547, p=.003$ accounting for $45.8 \%$ of the variance. The quadratic component was due to the children talking less at $\mathrm{M}$, and the linear component was due to their talking more at $\mathrm{M}-1$ than $\mathrm{M}+1$. At FW, children were more likely to be talking at $\mathrm{M}-1$ than at either $\mathrm{M}, t(10)=$ $-6.54, p<.001$ or $M+1, t(10)=3.85, p=.003$ (child talk at $M$ was not different from talk at $M+1, t(10)=-1.46, p$ $=.176)$. When the one-way repeated measures analysis was performed using only the data from the children with 3 or more targets at FW $(n=9)$, the deviations from baseline from M-1 through M and $M+1$ continued to be significant, $\mathrm{F}(2,16)=14.49, p<.001$.

The same pattern was obtained at VS, with a significant effect of time, $\mathrm{F}(2,20)=57.93, p<$.oo1. Results from the trend analyses revealed that a quadratic curve again explained the pattern of deviations from baseline, $t(10)$ $=8.56171, p<.001$, with a linear trend from $\mathrm{M}-1$ to $\mathrm{M}+1, t(10)=-6.12621, p<.001$. At VS, the quadratic component accounted for more of the variance (63.4\%) than the linear trend (32.4\%). The children were more likely to be talking relative to baseline at M-1 than at either $\mathrm{M}, t(10)=9.90, p<.001$ or $\mathrm{M}+1, t(10)=6.13, p<$ .001. In addition at VS, children were more likely to be talking relative to baseline at $\mathrm{M}+1$ than at $\mathrm{M}, t(10)=5.19$, $p<$.o01. When the one way repeated measures analysis of variance was performed with 12 children, to include the child from whom data were also available at VS, the effect of time continued to be significant, $\mathrm{F}(2,22)=$ $68.81, p<.001$.

The differences between FW and VS reflected development on the part of the children that complemented the increased responsivity from their mothers. At VS, the children were more likely to be talking relative to baseline than they were at FW immediately before mother speech $(\mathrm{M}-1), t(10)=5.95, p<.001$, and less likely at VS than at FW to be talking at the same time (at M), $t(10)=4.08, p=.002$. The difference between FW and VS in child speech occurring immediately after their mothers spoke $(\mathrm{M}+1)$, relative to baseline, was not significant, $t(10)=$ $-1.19, p=.262$.

Thus, the temporal contingency of turn-taking, a critical dimension of conversational interaction, was already evident at FW, with children most likely to talk before mother speech, and mothers most likely to be talking after child speech, relative to their respective baselines. The temporal patterning of turn taking was consolidated in the period of word learning between FW and VS, with greater excursions from baseline rates at VS than at FW. Both the mothers and children were more variable at VS than they had been at FW. Nevertheless, all the children and all the mothers showed the same profiles as the average profiles presented in Figures 1 and 2.

\section{Form and Function of Topic-Related Speech}

Analyses of topic-sharing and the form and function of topic-related speech were based on data from 11 children at FW and 12 at VS. Together, the children produced 105 utterance tokens in the first half hour at FW (M = 9.55) and 1,112 utterances in the first half hour at VS (M =92.67). The number of adjacency pairs (mother and child speech occurring within 2 secs) is shown in Table 3, along with the frequencies of topic-related adjacency pairs and topic-related pairs that were discourse- or action-related. The children initiated significantly more sequences than their mothers did, both at FW, $t(10)=2.37, p=.04$, and VS, $t(11)=5.04, p<.001$. The high standard deviations at FW were due to differences among the children and the small number of utterances. The children were far less variable at VS, when approximately half their speech was adjacent to something their mothers had just said (mother $\rightarrow$ child sequences), and two thirds of their adjacent speech shared the topic of prior mother speech. Many of these topic-related responses by the children were repetitions $(\mathrm{M}=40.6 \%, \mathrm{SD}=22.6 \%)$. 
Table 3. Number, Mean Proportion, and Standard Deviation of Child Speech in Adjacency Pairs, at FW and VS

\begin{tabular}{|c|c|c|c|c|}
\hline & \multicolumn{4}{|c|}{ CONVERSATION SEQUENCE } \\
\hline & \multicolumn{2}{|c|}{$\mathrm{M} \rightarrow \mathrm{CH}$} & \multicolumn{2}{|c|}{$\mathrm{CHI} \rightarrow \mathrm{M}$} \\
\hline & FW & VS & FW & VS \\
\hline 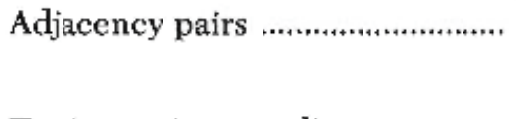 & $\begin{array}{c}45 \\
.383 \\
(.335)\end{array}$ & $\begin{array}{c}614 \\
.53 \\
\quad(.186)\end{array}$ & $\begin{array}{l}60 \\
582 \\
(292)\end{array}$ & $\begin{array}{r}776 \\
.678 \\
(.214)\end{array}$ \\
\hline 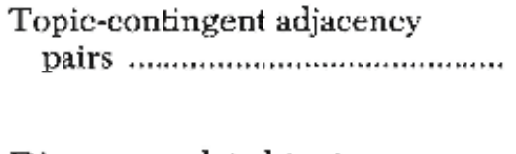 & $n=31^{\mathrm{a}, \mathrm{b}}$ & $\begin{array}{r}385 \\
.64 \\
(.18)\end{array}$ & $\begin{array}{l}51 \\
.889 \\
(.215)\end{array}$ & $\begin{array}{r}652.837 \\
(.123)\end{array}$ \\
\hline $\begin{array}{l}\text { Discourse-related topic- } \\
\text { contingent pairs }\end{array}$ & $n=29$ & $\begin{array}{r}344 \\
.869 \\
(.102)\end{array}$ & $n=41^{c}$ & $\begin{array}{r}572.858 \\
(.089)\end{array}$ \\
\hline 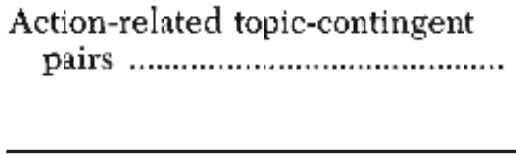 & $n=2$ & $\begin{array}{l}41 \\
1.13 \\
1.102)\end{array}$ & $n=8$ & $\begin{array}{l}80 \\
.096 \\
(.081) \\
\end{array}$ \\
\hline
\end{tabular}

a 21 of these were from 2 mother-child pairs.

${ }^{\mathrm{b}} n$ only is given for cells with low frequencies.

c 2 topic-contingent pairs were ambiguous and not coded as either discourse- or action-related.

Comparisons of child and mother speech at VS that shared the topic of a prior turn are shown in Figure 3. Little more than half of the children's speech in the half hour session received a topic-related response from their mothers at VS (Child $\rightarrow$ Mother sequences, $n=$ all child speech). However, mothers were strongly inclined to share the child's topic when their speech was adjacent at both FW and VS, with no significant difference between the two language achievements, $t(10)=.673, p=.516$. Only about one third of the children's speech occurred as a topic-related response to speech from their mothers (Mother $\rightarrow$ Child sequences, $n=$ all child speech); however, about two thirds of the Mother $\rightarrow$ Child adjacent speech was topic-related. At VS, mothers' adjacent speech (in Child $\rightarrow$ Mother sequences) shared child topic significantly more often than adjacent child speech (in Mother $\rightarrow$ Child sequences) shared the mothers' topic, $t(11)=-4.089, p=.002$.

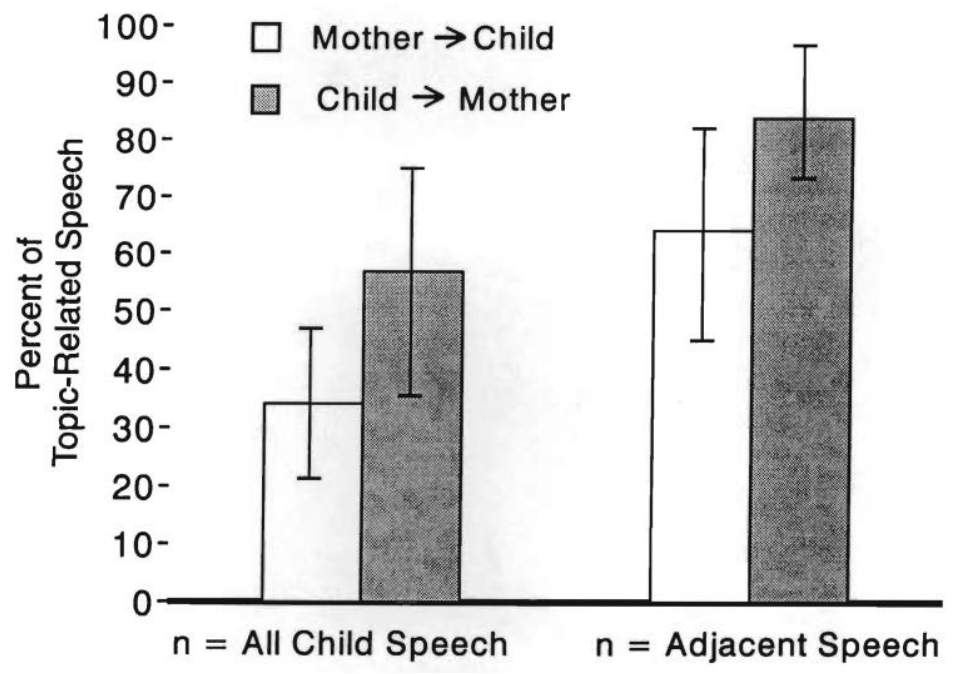

Figure 3. Mean percent of all child speech at VS that was topic-related in Mother $\rightarrow$ Child and Child $\rightarrow$ Mother pairs, and mean percent of only the adjacent speech in Mother $\rightarrow$ Child and Child $\rightarrow$ Mother pairs that was topic-related, $n=12$. The bars represent the means; the lines extend to $1 \mathrm{SD}$ above and below the mean. 


\section{Mothers' Topic Initiations at VS}

Question/answer Mother Child adjacency pairs (see Levinson, 1983) accounted for about half of the children's topic-related responses on average $(\mathrm{M}=51.7 \%, \mathrm{SD}=22.9)$. Half the mothers asked more questions, and half made more statements. The children were also evenly split with respect to whether their contingent speech occurred more often in response to a statement or a question by their mothers. However, the children's tendency to respond and share the topic after a question was not related to the frequency of prior mother turns that were questions, $\mathrm{r}(10)=.203$. Children whose mothers ask more questions have sometimes been described as more precocious language learners (Furrow, Nelson, \& Benedict, 1979; Newport, Gleitman, \& Gleitman, 1977). However, age at VS was not correlated with either the percentage of topic-related speech in response to mother questions, $\mathrm{r}(10)=.375$, or the percentage of the preceding mothers' utterances that were questions, $\mathrm{r}(10)=.230$.

Children shared the topic most often when mothers' speech functioned as discourse commentary and less often when mothers encouraged or discouraged their actions (Table 3). The functions of mothers' topic-related speech that was discourse-related at VS are shown in Figure 4, for both initiations (in Mother $\rightarrow$ Child sequences) and responses (in Child $\rightarrow$ Mother sequences). More than half the mothers' initiations encouraged a child to say something (for example, "What's the cow say?"), and about one third were assessment/descriptions (for example, "That's a baby cow").

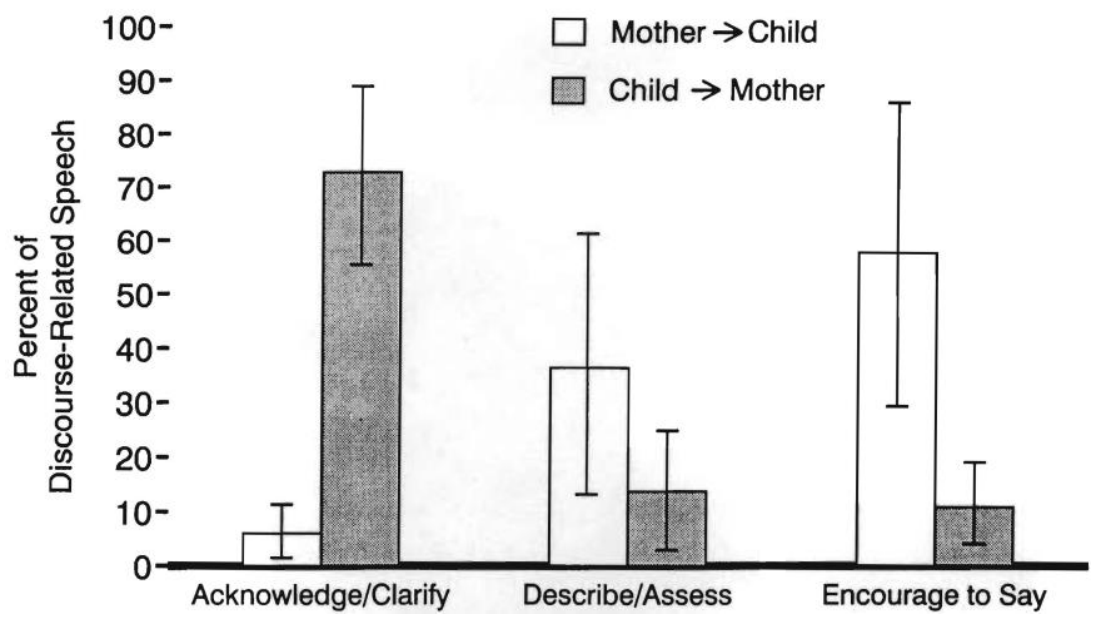

Figure 4. Mean percent of the functions of Mother topic-related speech that was discourse-related in Mother $\rightarrow$ Child and Child $\rightarrow$ Mother pairs at VS, $n=12$. The bars represent the means; the lines extend to $1 \mathrm{SD}$ above and below the mean.

\section{Mothers' Responses at VS}

More than half the mothers' topic-related responses repeated what the child said $(\mathrm{M}=59.2 \%, \mathrm{SD}=18.8)$. Whether they repeated or not, mothers were, in general, more likely to respond with a statement $(\mathrm{M}=68.8 \%$, SD $=13.8$ ) than a question (the exceptions were one mother who responded more often with a question, and another who asked as many questions).

Overall, encouraging a child to act was the function of only $8.3 \%$ of mother responding (only 5 mothers responded to child speech by discouraging the child from acting). Discourse-related responding predominated, making up $86 \%$ of the interactions on average at VS, and the functions of mother responding (in Child $\rightarrow$ Mother sequences) are also shown in Figure 4. Most often, mothers simply acknowledged what the child said or asked for clarification (for example, "more? did you say more?"), something the children did not do. Mothers encouraged their children to say something else or responded with a description/assessment $24.5 \%$ of the time. In sum, when mothers shared the child's topic in responding, they typically just repeated or otherwise acknowledged what the child had just said, and they were more likely to make a statement than to ask a question. Thus, while they were taking a turn to keep the conversation going, they were not likely to make "extended replies," such as Howe (1981) described with somewhat older children. 


\section{Extended Conversations}

In the final analysis, we looked at the development of sequences in turn taking and topic sharing that extended across 3 or more turns with at least 1 turn each by child and mother. Such conversations were infrequent at FW (only 38 in the interactions of 7 mother-child pairs, with 17 from one pair, 8 from 2 others, and none in the interactions of 5 children).

At VS, the children and their mothers participated in 416 extended conversations $(\mathrm{M}=33.67, \mathrm{SD}=18.82$, range $=6$ to 59), and these varied in length from 3 to 17 turns. However, most consisted of only 3 turns (mode $=3$ turns for all mother-child pairs) as reported also by Kaye and Charney (1980), and the average mean length of conversations was 4.18 turns ( $\mathrm{SD}=.54$, range $=3.3$ to 5.3 ). Conversational sequences were most often initiated by the mothers ( $\mathrm{M}=78.6 \%)$, and the mothers most often ended them as well ( $\mathrm{M}=89.5 \%)$. Thus, conversations longer than 3 turns consisted, for the most part, of a mother responding to her child's response to her; the children rarely had the last word.

In a post hoc analysis, we tested the limit of 5 seconds we had imposed on counting successive turns as related by examining the transcript for one child-mother pair; this pair had participated in 39 conversational sequences ranging in length from 3 to 11 turns at VS. Ignoring the 5 -s rule and counting any successive topic sharing as turns netted only 2 additional conversations. Both contained just 3 turns, and both began and ended with turns by the mother. The length of one other conversation that had already been counted was extended by an additional child turn. Thus, the results would not have been appreciably different without the 5 -s rule.

\section{DISCUSSION}

This study of early conversations encompassed two achievements in word learning in the single-word period and provided evidence of the kinds of experiences with language that young children have as they are learning words. The results support a model of language development that takes a young child's intentional states as the starting point (Bloom, 1993a; Bloom \& Beckwith, 1989). Participation in these earliest conversations was motivated by a child's own cognitive agenda to express something in mind, and conversations functioned to allow the children to direct the flow of the interaction in order to express and thereby share what was relevant to them. Their conversations did not depend on mothers setting up linguistic formats as the occasions for their interactions and word learning; the scaffolding model was not supported. These results are consistent with a recent longitudinal study in which the scaffolding model for language learning was explicitly tested using interactional games between mothers and infants from 9 to 24 months; mothers' scaffolding behaviors were not related to children's language ability (Rome-Flanders, Cronk, \& Gourde, 1995).

The single-word period in the second year is bracketed by two well-documented developments in the origins of conversation, and the results of this study were continuous with both. The later development occurs as 2-yearolds acquire a grammar, and the semantic and formal relatedness between child and adult messages increases. Children in an earlier study (Bloom, Rocissano \& Hood, 1976) learned to share the topic of a prior utterance by using the information they interpret from what someone else says to construct a new representation for expression (see, also, Howe, 1981). The younger children in the present study who were just learning words were sharing the topic of a prior mother turn with $34 \%$ of all their speech and $64 \%$ of just their adjacent speech, by the time they reached VS. These results complemented the findings with the somewhat older children studied by Bloom et al., who were just beginning to say sentences; those children shared the prior adult topic on average with $39 \%$ of their speech overall and $56 \%$ of just their adjacent speech. Imitations figured prominently in how the older children maintained discourse topic, amounting to $46 \%$ of their topic-related speech on average; similarly, the children in the present study also relied on repetition with an average $41 \%$ of their topic-related single words. (See Bloom, Rocissano \& Hood, 1976; Keenan, 1974; and Greenfield \& Savage-Rumbaugh, 1993, for analyses and discussion of the pragmatics of repetition in discourse.)

The results of this study are also continuous with earlier developments in prelinguistic communication before language. As expected from studies in the literature of mothers responding to infant vocalizing before language (e.g., Beebe et al., 1985; Roth, 1987; Schaffer, Collins, \& Parsons, 1977), the mothers of the 1-year-olds in this study were most likely to be talking in the 1 and 2 seconds after their children said something. Such continuity in 
the form of interaction indicates that scaffolding is not required for also learning to participate in conversation when children are learning words.

Mothers were strongly inclined to continue a child's topic when responding to them at both FW and VS (84\% on average), and this result is consistent with reports by Chapman, Miller, MacKenzie, \& Bedrosian (1981) for children in the same age range and by Howe (1981) with slightly older children. Most mother responding to what her child said functioned to continue the discourse rather than to encourage or discourage actions, and most of this discourse-related speech acknowledged or clarified what the child had said, typically by repeating it. One might want to consider such high rates of mother responding a "weak" form of scaffolding. However, topicsharing is integral to both the form and content of conversation and indicates that perspectives have been shared (e.g., Bloom, Rocissano, \& Hood, 1976; Keenan \& Schieffelin, 1976; Shatz, 1983); it is not merely the external format for the exchange.

The children initiated more conversations than their mothers did at both FW and VS, and only about a third of the children's speech in this study occurred in response to something their mothers said. This result is consistent with reports by Chapman et al. (1981), Harris (1992), and Howe (1981). More frequent Child $\rightarrow$ Mother than Mother $\rightarrow$ Child sequences could be interpreted to mean that mothers are just better responders, as Howe concluded. However, using the baseline rates of speech for the on-line analyses of temporal contingency revealed that mothers were more likely to respond than might be expected from their rates of talking overall. If mothers had talked a great deal to elicit speech because children weren't very good at responding, then they would have talked much more relative to their baseline rates in the moments before children's speech. But they did not, which means that mothers were strongly inclined to talk in response to their children, while their children were strongly inclined to say something to initiate an exchange.

Although mothers were better at responding and shared the child's topic in $84 \%$ of the Child $\rightarrow$ Mother adjacency pairs, in fact, only about half of all the children's speech in the playroom received a topic-related response. And when responding, mothers were most likely to simply repeat, acknowledge, and/or attempt to clarify what a child had said, and more likely to respond with a statement than with a question. The "turnarounds" reported by Kaye and Charney (1980) were infrequent, but their conclusion that mothers were responsible for creating and maintaining dialogue was based on analysis of only the first 5 minutes of two observations of mother-child pairs, one at 26 and another at 39 months. Mothers might well take the lead in their interactions at the start of a session, particularly in a situation that is new for a child, as the results of the study by Lucariello (1987) would suggest. We concluded that the mothers of the 1-year-olds we studied were more interested in maintaining a conversation by letting a child know that a message had been shared than in providing language models for the child to learn.

The playroom activities did not include picture book reading, script-like play such as a tea party, or direct instruction-activities that, in fact, make up only a small part of what happens between caregivers and young children in the course of a day. These are activities in which the mothers' privileged role might have encouraged them to take charge and be more directive. By studying activities in which mothers did not necessarily have an advantage in the exchange, we were able to demonstrate the importance of the children's contribution to their developing conversations. The picture that emerged differed from traditional accounts of scaffolding and conversational asymmetry. Both child and mother contributed to the architecture of the early conversations between them, but, in fact, it was the children who were in charge.

The children evidently already knew the words they used in their conversations, and a question that remains is how they learned them if they did not learn them in scaffolded interactions. Children are clearly learning words in many different kinds of contexts, but we suggest that this is most likely to happen when they are not pressed or otherwise expected to reply, as in a conversation. Accounts of word learning do not ordinarily give much attention to the part that observational learning plays in language development. However, strong effects of observational learning have been demonstrated in other contexts (e.g., Hanna \& Meltzoff, 1993) and even with nonhuman species (Fiorito \& Scotto, 1992). It should not be surprising, therefore, that children learn new words by hearing or overhearing words that are relevant to what they have in mind, without having to participate in specifically linguistic formats at the same time. 
The principle of relevance is the first principle of the Intentionality model in Bloom (1993a), complementing the principles of discrepancy and elaboration. According to the principle of relevance, language learning is enhanced when the speech a child hears bears upon and is pertinent to what the child is attending to or otherwise thinking about (Bloom, 1993a). "Relevance is the single property that makes information worth processing and determines the particular assumptions an individual is most likely to construct and process" (Sperber \& Wilson, 1986, p. 46). The principle of relevance captures the fact that observational learning is particularly enhanced when children hear and overhear speech that bears on what they are feeling, thinking, and doing. The mothers in this study were talking to their children, and some of them were talking a great deal, as is evident from their baseline rates and numbers of targets in Table 1. And, indeed, most of their talk was about the children and what they were doing-providing them with the relevant experiences they needed for the words they were learning. Word learning can occur in very many of these contexts without an expectation for the child to say something at the time. Similarly, children take in a great deal and learn about what goes on around them outside of language, without having to show the effects of that learning in their immediate nonlinguistic actions and behaviors.

The language a child brings to a conversation, therefore, is language already learned from what has been heard and overheard in a multitude of actions and interactions that have come before. These situations do not have to be set up for them. In fact, young children are better able to recruit cognitive resources for language when their essentially limited resources are not also stretched by having to process and respond to what someone else has just said (Bloom, 1993a; Bloom, Miller, \& Hood, 1975; Bloom, Rocissano, \& Hood, 1976; Elbers \& Wijnen, 1992). Indeed, this point gains considerable support from studies of children talking in their cribs alone, before falling off to sleep. More sophisticated forms of language occur in "crib speech" than are observed in typical daytime interactions with other persons (Kuczaj, 1983; Nelson, 1990; Weir, 1964) because children have greater "freedom to direct their own behavior" (Kuczaj, 1983, p. 168).

The force of the Intentionality model is enhanced when one considers that the same patterns of results were obtained with all the children, even when they differed in certain respects. For example, at VS, the children and mothers from the poorest families in our sample had the fewest extended conversations, which is consistent with other reports of the effects of limited economic resources on family interactions (e.g., Hart \& Risley, 1994). These same child-mother pairs were also more likely than the others to be close to their own baseline rates of speaking when one or the other was speaking, meaning they were more likely to be talking at the same time. Overlapping turns are evidently acceptable in culturally different societies and even valued by the participants in certain contexts (e.g., Cazden \& Dickinson, 1981; Ervin-Tripp, 1979; Heath, 1982, 1983; Whatley, 1981). But regardless of possible economic and/or cultural effects on their behaviors, the children from the poorest homes were also the initiators and in charge of their conversations, and their mothers were responsive to them. As with the other children, they were most likely to be talking in the moments before their mothers talked, and their mothers were most likely to be talking in the moments after they talked. Thus, we have no reason to think that the process of learning language differed; the same principles of relevance, discrepancy, and elaboration in an Intentionality model captured this process for all the children.

When looking to explain how children learn words, a frequent tendency in the literature is to look for influences from factors either outside of the child, such as scaffolding (e.g., Ninio \& Bruner, 1978) and relative economic resources (e.g., Hart \& Risley, 1995), or inherent preconditions within the child, such as lexical constraints or biases to guide word learning (e.g., Markman, 1989, 1992; Waxman \& Markow, 1995). However, both sorts of explanation ignore the child's Intentionality as a person with thoughts and feelings in consciousness that are about something. It is what a child's intentional states are about, and children's strong inclinations to express their Intentionality by acting to share intentional states with other persons, that determine why and how language is learned. 


\title{
APPENDIX
}

\section{Coding Categories for Forms and Functions \\ of Mothers' Speech}

\author{
Forms of Mothers' Adjacent Speech \\ Statement \\ Question \\ Repetition (of all or part of a previous child turn), for example \\ Ch: car. \\ M: Yes, it's a car. \\ Functions of Mothers' Adjacent Speech \\ Action related, either to \\ Encourage action, for example, \\ M: Here have some juice. \\ M: Wanna put the daddy in the truck? \\ Discourage action, for example, \\ M: You can't fit in there.

\section{Discourse-related} \\ Acknowledgement, 3 for example, \\ Ch: Pig. \\ M: Pig, yeah, that's right. \\ Clarification, for example, \\ Ch: "up." \\ M: "up? Did you say 'up'. \\ Encourage Talk, for example, \\ $\mathrm{M}$ : What's that? \\ M: You know what a horse says? \\ M: Isn't that nice? \\ Description/Assessment, for example, \\ $\mathrm{M}$ : This is the mommy. \\ M: The baby's hungry. \\ M: The beads are all over the floor.
}

3 A mother's utterance was a clarification or acknowledgement when she said something before her child said something, if what she said was also a response to a prior utterance by the child (in a child $\rightarrow$ mother child extended conversation. 


\section{REFERENCES}

Bakeman, R. (1978). Untangling streams of behavior: Sequential analyses of observational data. In G. Sackett (Ed.), Observing behavior (Vol. II, Data collection and analysis methods, pp. 63-78). Baltimore, MD: University Park.

Bateson, C. (1975). Mother-infant exchanges: The epigenesis of conversational interaction. In D. Aronson, \& R. Rieber (Eds.), Development psycholinguistics and communication disorders. Annals of the New York Academy of Sciences, 263, 101-113.

Beckwith, R. (1988). Learnability and psychological categories. Unpublished Ph.D. dissertation, Columbia University.

Beckwith, R., Bloom, L., Albury, D., Raqib, A., \& Booth, R. (1985). Technology and methodology. Transcript Analysis, 2, 72-75.

Beebe, B., \& Jaffe, J. (1992). Mother-infant vocal dialogues. Paper presented at the International Conference on Infant Studies, Miami.

Beebe, B., Jaffe, J., Feldstein, S., Mays, K., \& Alson, D. (1985). Interpersonal timing: The application of an adult dialogue model to mother-infant vocal and kinesic interaction. In T. Field \& N. Fox (Eds.) Social perception in infants (pp. 217-247). Norwood, NJ: Ablex.

Bloom, K. (1977). Patterning of infant vocal behavior. Journal of Experimental Child Psychology, 17, 250-263.

Bloom, K. (1990). Selectivity and early infant vocalization. In J. Enns (Ed.), The development of attention: Research and theory (pp. 121-136). North-Holland: Elsevier Science.

Bloom, K., Russell, A., \& Wassenberg, K. (1987). Turn-taking affects the quality of infant vocalization. Journal of Child Language, 14, 211-227.

Bloom, L. (1970). Language development: Form and function in emerging grammars. Cambridge, MA: MIT Press.

Bloom, L. (1973). One word at a time: The use of single-word utterances before syntax. The Hague: Mouton.

Bloom, L. (1993a). The transition from infancy to language: Acquiring the power of expression. Cambridge: Cambridge University Press.

Bloom, L. (1993b). Transcription and coding for child language research: The parts are greater than the whole. In J. Edwards \& M. Lampert (Eds.), Transcription and coding methods for language research (pp. 149-166). Hillsdale, NJ: Erlbaum.

Bloom, L., and Beckwith, R. (1989a). Intentionality and Language Development. Unpublished manuscript.

Bloom, L., \& Beckwith, R. (1989b). Talking with feeling: Integrating affective and linguistic expression. Cognition and Emotion, 3, 313-342.

Bloom, L., Beckwith, R., Capatides, J., \& Hafitz, J. (1988). Expression through affect and words in the transition from infancy to language. In P. Baltes, D. Featherman, \& R. Lerner (Eds.), Life-span development and behavior (Vol. 8, pp. 99-127). Hillsdale, NJ: Erlbaum.

Bloom, L., \& Capatides, J. (1987). Expression of affect and the emergence of language. Child Development, 58, 15131522.

Bloom, L., Miller, P., \& Hood, L. (1975). Variation and reduction as aspects of competence in language development. In A. Pick (Ed.), Child psychology: Minnesota Symposia on Child Psychology (Vol. 9, pp 3-55). Minneapolis: University of Minnesota Press.

Bloom, L., Rocissano, L., \& Hood, L. (1976). Adult-child discourse: Developmental interaction between information processing and linguistic knowledge. Cognitive Psychology, 8, 521-552.

Bloom, L., Tinker, E., \& Margulis, C. (1993) The words children learn: Evidence against a noun bias in early vocabularies, Cognitive Development, 8, 431-450.

Bruner, J. (1977). Early social interaction and language acquisition. In H. Schaffer (Ed.), Studies in mother-infant interaction (pp. 271-289). London: Academic Press.

Bruner, J. (1983a). Child's talk, learning to use language. New York: W.W. Norton. 
Bruner, J. (1983b). The acquisition of pragmatic commitments. In R. Golinkoff (Ed.), The transition from prelinguistic to linguistic communication (pp. 27-42). Hillsdale, NJ: Lawrence Erlbaum Associates.

Camaioni, L. (1986). From early interaction patterns to language acquisition: Which continuity? In J. CookGumperz, W. Corsaro, \& J. Streeck (Eds.), Children's worlds and children's language (pp. 69-82). Berlin: Mouton de Gruyter.

Capatides, J. (1990). Mothers' socialization of their children's experience and expression of emotion. Unpublished Ph.D. dissertation, Columbia University.

Cazden, C., \& Dickinson, D. (1981). Language in education: Standardization versus cultural pluralism. In C. Ferguson \& S. Heath (Eds.), Language in the USA (pp. 446-468). Cambridge: Cambridge University Press.

Chapman, R., Miller, J., MacKenzie, H., \& Bedrosian, J. (1981, August). The development of discourse skills in the second year of life. Paper presented to the Second International Congress for the Study of Child Language, University of British Columbia, Vancouver, Canada.

Crystal, D. (1987). The Cambridge encyclopedia of language. Cambridge: Cambridge University Press.

Danto, A. (1973). Analytical philosophy of action. Cambridge: Cambridge University Press.

Danto, A. (1983). Toward a retentive materialism. In L. Cauman, I. Levi, C. Parsons, \& R. Schwartz (Eds.), How many questions? Essays in honor of Sidney Morgenbesser (pp. 243-255). Indianapolis, IN: Hackett Publishing.

Dore, J. (1983). Feeling, form, and intention in the baby's transition to language. In R. Golinkoff (Ed.), The transition from prelinguistic to linguistic communication (pp. 167-190). Hillsdale, NJ: Erlbaum.

Elbers, L., \& Wijnen, F. (1992). Effort, production skill, and language learning. In C. Ferguson, L. Menn, \& C. StoelGammon (Eds.), Phonological development: Models, research, implications (pp. 337-368). Timonium, MD: York Press.

Ervin-tripp, S. (1979). Children's verbal turn-taking. In E. Ochs, \& B. Schieffelin (Eds.), Developmental pragmatics (pp. 391-414). New York: Academic.

Fiorito, G., \& Scotto, P. (1992). Observational learning in Octopus vulgaris, Science, 256, 545-546.

Foster, S. (1986). Learning discourse topic management in the preschool years. Journal of Child Language, 13, 231250.

Furrow, D., Nelson, K., \& Benedict, H. (1979). Mother's speech to children and syntactic development: Some simple relationships. Journal of Child Language, 6, 423-442.

Goddard, M., Durkin, K., \& Rutter, D. (1985). The semantic focus of maternal speech: A comment on Ninio \& Bruner (1978), Journal of Child Language, 12, 209-213.

Goldfield, B., \& Reznick, J. (1990). Early lexical acquisition: Rate, content, and the vocabulary spurt. Journal of Child Language, 17, 171-183.

Goodnow, J. (1990). Using sociology to extend psychological accounts of cognitive development. Human Development, 33, 81-107.

Greenfield, P., \& Savage-Rumbaugh, S. (1993). Comparing communicative competence in child and chimp: The pragmatics of repetition. Journal of Child Language, 20, 1-26.

Hanna, E., \& Meltzoff, A. (1993). Peer imitation by toddlers in laboratory, home, and day-care contexts. Developmental Psychology, 29, 701-710.

Harris, M. (1992). Language experience and early language development: From input to uptake. Hove, NJ: Erlbaum.

Hart, B., \& Risley, T. (1995). Meaningful differences in the everyday experiences of young American children. Baltimore, MD: Brookes.

Heath, S. (1982). What no bedtime story means: Narrative skills at home and school. Language and Society, 11, 4976.

Heath, S. (1983). Ways with words. Cambridge: Cambridge University Press.

Howe, C. (1981). Acquiring language in a conversational context. London: Academic Press.

Howell, D. (1992). Statistical methods for psychology, 3rd ed. Boston: Duxbury Press. 
Jaffe, J., Stern, D., \& Peery, J. (1973). "Conversational" coupling of gaze behavior in prelinguistic human development. Journal of Psycholinguistic Research, 2, 321-329.

foundations of language and thought (pp. 211-230). New York: W. W. Norton \& Company.

Kaye, K. (1977). Toward the origin of dialogue. In H. Schaffer (Ed.), Studies in mother-infant interaction (pp. 89-117). London: Academic Press.

Kaye, K. (1979). Thickening thin data: The maternal role in developing communication and language. In M. Bullowa (Ed.), Before speech (pp. 191-206). Cambridge: Cambridge University Press.

Kaye, K., \& Charney, R. (1980). How mothers maintain 'dialogue' with two-year-olds. In D. Olson (Ed.), The social

Keenan, E. (1974). Conversational competence in children. Journal of Child Language, 1, 163-183.

Keenan, E., \& Schieffelin, B. (1976). Topic as a discourse notion: A study of topic in the conversations of children and adults. In C. Li (Ed.), Subject and topic (pp. 335-384). New York: Academic Press.

Kuczaj, S. (1983). Crib speech and language play. New York: Springer-Verlag.

Levinson, S. (1983). Pragmatics. Cambridge: Cambridge University Press.

Lifter, K. (1982). Development of object related behavior during the transition from prelinguistic to linguistic communication. Unpublished Ph.D. dissertation, Columbia University.

Lifter, K., \& Bloom, L. (1989). Object play and the emergence of language. Infant Behavior and Development, 12, 395-423.

Lucariello, J. (1987). Spinning fantasy: Themes, structure, and the knowledge base. Child Development, 58, 434-442.

Lucariello, J. (1995). Mind, culture, person: Elements in a cultural psychology. Human Development, 38, 2-18.

Lucariello, J., \& Nelson, K. (1987). Remembering and planning talk between mothers and young children. Discourse Processes, 10, 219-235.

Markman, E. (1989). Categorization and naming in children. Cambridge, MA: MIT Press.

Markman, E. (1992). Constraints on word learning: Speculations about their nature, origins, and domain specificity. In M. Gunnar \& M. Maratsos (Eds.), Minnesota symposia on child psychology (Vol. 25, pp. 59-101). Hillsdale, NJ: Erlbaum.

Menyuk, P., Liebergott, J., Schultz, M., Chesnick, M., \& Ferrier, L. (1991). Patterns of early lexical and cognitive development in premature and full-term infants. Journal of Speech and Hearing Research, 34, 88-94.

Mervis, C., \& Bertrand, J. (1995). Early lexical acquisition and the vocabulary spurt: A response to Goldfield \& Reznick. Journal of Child Language, 22, 461-468.

Moerk, E. (1989). The LAD was a lady and the tasks were ill-defined. Developmental Review, 9, 21-57.

Nelson, K. (1973). Structure and strategy in learning to talk. Monographs of the Society for Research in Child Development, 38, No. 149.

Nelson, K. (1990). Narratives from the crib. Cambridge, MA: Harvard University Press.

Newport, E., Gleitman, L., \& Gleitman, H. (1977). Mother, I'd rather do it myself: Some effects and non-effects of maternal speech style. In C. Snow \& C. Ferguson (Eds.), Talking to children: Language input and acquisition. Cambridge: Cambridge University.

Newson, J. (1978). Dialogue and development. In A. Lock (Ed.), Action, gesture, and symbol: The emergence of language (pp. 31-42). London: Academic Press.

Ninio, A., \& Bruner, J. (1978). The achievement and antecedents of labelling. Journal of Child Language, 5, 1-15.

Ochs, E., \& Schieffelin, B. (1984). Language acquisition and socialization: Three developmental stories. In R. Shweder \& R. Levine (Eds.), Culture theory: Essays in mind, self and emotion (pp. 276-320). New York: Cambridge University Press.

Ratner, N., \& Bruner, J. (1978). Games, social exchange, and the acquisition of language. Journal of Child Language, $5,391-401$.

Rogoff, B. (1990). Apprenticeship in thinking: Cognitive development in social context. New York: Oxford University Press. 
Rogoff, B. (1993). Children's guided participation and participatory appropriation in sociocultural activity. In R. Wozniak \& K. Fischer (Eds.), Development in context: Acting and thinking in specific environments (pp. 121153). Hillsdale, NJ: Erlbaum.

Rome-Flanders, T., Cronk, C., \& Gourde, C. (1995). Maternal scaffolding in mother-infant games and its relationship to language development: A longitudinal study. First Language, 15, 339-355.

Roth, P. (1987). Temporal characteristics of maternal verbal styles. In K. Nelson \& A. van Kleek (Eds.), Children's language, 6, 137-158). Hillsdale, NJ: Erlbaum.

Sackett, G. (1974). A nonparametric lag sequential analysis for studying dependency among responses in behavioral observation scoring systems. Unpublished paper presented at the Western Psychological Association, San Francisco.

Sackett, G. (1979). The lag sequential analysis of contingency and cyclicity in behavioral interaction research. In Osofsky, J. (Ed.), Handbook of infant development (pp. 623-649). New York: John Wiley.

Schaffer, H., Collis, G., \& Parsons, G. (1977). Vocal interchange and visual regard in verbal and pre-verbal children. In H. Schaffer (Ed.), Studies in mother-infant interaction (pp. 291-324). London: Academic Press.

Searle, J. (1983). Intentionality: An essay in the philosophy of mind. Cambridge: Cambridge University Press.

Shatz, M. (1983). Communication. In J. Flavell \& E. Markman (Eds.), P. Mussen, (Series Ed.), Handbook of child psychology: Vol. 3. Cognitive development (pp. 841-890). New York: John Wiley \& Sons.

Snow, C. (1977). The development of conversation between mothers and babies. Journal of Child Language, 4, 1-22.

Snow, C., \& Goldfield, B. (1983). Turn the page please: Situation-specific language acquisition, Journal of Child Language, 10, 551-569.

Sperber, D., \& Wilson, D. (1986). Relevance: Communication and Cognition. Cambridge, MA: Harvard University Press.

Stern, D., Jaffe, J., Beebe, B., \& Bennett, S. (1975). Vocalizing in unison and in alternation: Two modes of communication within the mother-infant dyad. In D. Aronson, \& R. Rieber (Eds.), Developmental psycholinguistics and communication disorders. Annals of the New York Academy of Sciences, 263, 89-100.

Taylor, C. (1979). Action as expression. In C. Diamond \& J. Teichman (Eds.), Intentions and intentionality, Essays in honor of G. E. M. Anscombe (pp.73-89). Ithaca, NY: Cornell University Press.

Taylor, C. (1985). Philosophical papers: Vol. 1. Human agency and language. Cambridge: Cambridge University Press.

Tomasello, M. (1992). The social bases of language acquisition. Social Development, 1, 67-87.

Tomasello, M., \& Farrar, J. (1986). Joint attention and early language. Child Development, 57, 1454-1463.

Trevarthen, C. (1977). Descriptive analysis of infant communication behavior. In H. Schaffer (Ed.), Studies in motherinfant interaction (pp. 227-270). London: Academic Press.

Vygotsky, L. (1962). Thought and language. Cambridge MA: The MIT Press.

Vygotsky, L. S. (1978). Mind in society: The development of higher psychological processes (M. Cole, V. JohnSteiner, S. Scribner \& E. Souberman., Eds.) (A. R. Luria, M. Lopez-Morillas \& M. Cole [with J. V. Wertsch], Trans.) Cambridge, Mass.: Harvard University Press. (Originally published 1930-1934).

Waxman, S., \& Markow, D. (1995), Words as invitations to form categories: Evidence from 12- to 13-month-old infants. Cognitive Psychology, 29, 257-302.

Whatley, E. (1981). Language among Black Americans. In C. Ferguson \& S. Heath (Eds.), Language in the USA (pp. 92-107). Cambridge: Cambridge University Press.

Weir, R. (1964). Language in the crib. The Hague: Mouton.

Wood, D., Bruner, J., \& Ross, G. (1976). The role or tutoring in problem solving. Journal of Psychology and Psychiatry, 17, 89-100. 